\title{
Personalidade e Câncer de Mama e do Aparelho Digestório ${ }^{1}$
}

\author{
Márcia Fernandes Bandeira \\ Valéria Barbieri² \\ Universidade de São Paulo - Campus Ribeirão Preto
}

\begin{abstract}
RESUMO - Como a literatura indica influência de características de personalidade na formação do câncer, este estudo objetivou verificar se elas seriam gerais ou variariam segundo o tipo de neoplasia. Foram aplicadas entrevistas psicológicas e forma reduzida do TAT em 15 mulheres entre 41 e 60 anos, distribuídas em um grupo de 10 com câncer de mama (CM) e outro de cinco com câncer do aparelho digestório (CAD). Resultados revelaram predominância de organizações de personalidade borderline no grupo CM e neurótica no CAD. Ambos os grupos apresentaram perdas e frustrações antecedendo a doença, clivagem do ego entre razão e afeto, conflitos entre pulsões agressivas e sexuais e com figura materna e predomínio do pensamento operatório, indicando dificuldade de representação psíquica das pulsões. Foram realizadas considerações relativas à importância da psicoterapia com pacientes neoplásicos, auxiliando na construção e fortalecimento da capacidade de simbolizar.
\end{abstract}

Palavras-chave:câncer; personalidade; psicossomática; psico-oncologia; Teste de Apercepção Temática.

\section{Personality and Breast Cancer and Digestive Apparatus Cancer}

\begin{abstract}
The psycho-oncology literature points to influences of personality characteristics in cancer origin. This present study aimed to verify psychological aspects involved in the etiology of breast and digestive apparatus cancer, in a comparative study. It was accomplished through the application of a psychological interview and a reduced form of Thematic Apperception Test (TAT), in 15 women patients between 41 and 60 years old, divided in two groups: breast cancer (BC) and digestive apparatus cancer (DAC). Results indicated predominance of borderline personality organizations in BC and neurotic personality structures in DAC. Both groups referred losses and frustrations preceding disease, splitting of the ego between reason and affect, conflicts between aggressive and sexual instincts, conflicts relating to maternal figure and prevalence of operative thought, indicating difficulties in representing their own instincts mentally. Considerations were made about the importance of psychoterapy in these patients in order to construct or strength their symbolic capability.
\end{abstract}

Key words: cancer; personality; psychosomatic; psychooncology; Thematic Apperception Test.

A ligação mente-corpo já era citada por Freud (1923/1997) em sua segunda tópica, postulando que o id, como instância psíquica originada pela atividade corporal, ao entrar em contato com a esfera social, propicia o aparecimento do ego, que faz a mediação dos mundos interno e externo. Freud mostra, portanto, que o indivíduo é uma unidade psíquica, social e orgânica; diante disso, pode-se dizer que suas doenças físicas derivam não só de uma disfunção orgânica, como também do ambiente social e da sua vida psíquica, com seus afetos e relações objetais. Perestrello (1996) afirma que por ser o homem um todo psicossomático, todas as doenças são psicossomáticas.

De acordo com McDougall, todos nós temos tendência à somatização quando circunstâncias externas ou internas

1 Apoio financeiro: FAPESP. Apresentações em congressos: resultados parciais apresentados na XXXIII Reunião Anual da Sociedade Brasileira de Psicologia, realizada em Belo Horizonte - MG, de 22 a 26 de outubro de 2003 e resultados globais apresentados na XXXIV Reunião Anual da Sociedade Brasileira de Psicologia, realizada em Ribeirão Preto - SP, de 26 a 29 de Outubro de 2004. Gostaríamos de agradecer à Prof ${ }^{a} \operatorname{Dr}^{a}$ Eucia Beatriz Lopes Petean, por sua contribuição para esse trabalho.

2 Endereço: Av. Bandeirantes, 3900, Campus da USP, FFCLRP, Departamento de Psicologia e Educação, Ribeirão Preto, SP, Brasil 14040-901. E-mail: valeriab@ffclrp.usp.br ultrapassam os nossos "modos psicológicos de resistências habituais" (1996, p.3). Nesse sentido, Marty (conforme citado por Vieira, 1997) diz ter a capacidade de assimilação mental ("mentalização"), limites maiores ou menores conforme os indivíduos e em um mesmo indivíduo, de acordo com o momento de sua vida. Segundo Marty (1993), o traumatismo em psicossomática corresponde à ultrapassagem das possibilidades de adaptação do sujeito e causa desorganização dos aparelhos mental e somático. As situações traumatizantes provocam uma alteração na economia das excitações instintuais para o excesso, queda ou combinação de ambos, que acarretariam "transbordamentos passageiros do aparelho mental, (...) apelando para mecanismos somáticos" (p.14).

Para alguns autores (Épinay, 1988; Ferraz, 1997; McDougall, 1996) as origens dos fenômenos psicossomáticos podem ser encontradas na primeira infância, na relação com os pais, principalmente com a mãe. A pesquisa em psicossomática tem encontrado nas relações mãe-bebê a base de perturbações que influenciam a estruturação das defesas, diferenciando o somatizador do neurótico (Ferraz, 1997). Zimermam (1999) afirma ser consenso que a "gênese da predisposição psicossomática reside nas vivências emocionais, narcísicas e sensuais que caracterizaram os primitivos vínculos do bebê com a sua mãe" (p. 249). 
Para Bergeret (1998), as psicossomatizações existem em indivíduos com qualquer estrutura de personalidade, mas encontram-se mais próximas daqueles com organização limítrofe. Perestrello (1996) diz que algumas pessoas, por não terem encontrado melhor solução para um "impasse existencial", desenvolvem uma doença como negação dessa situação de conflito.

Entre a multiplicidade de fatores (psíquicos e fisiológicos) envolvidos na gênese do fenômeno psicossomático, as situações de perda, antecedendo a enfermidade, são enfatizadas na literatura (Mello Filho, 1994). A vulnerabilidade do ego à frustração (causada pela perda) pode ser condição para a predisposição psíquica ao adoecer.

Para Marty (1993), "o problema central das somatizações está no "fluxo das excitações instintuais e pulsionais, de essência agressiva e erótica” (p. 31). Essas excitações necessitam de elaboração psíquica e vias de expressão em traços de caráter e comportamento. A impossibilidade desse fluxo conveniente estaria relacionada com a "insuficiência fundamental do sistema pré-consciente das representações" (p. 31), podendo resultar em afecções somáticas. O préconsciente é peça central da economia psicossomática por ser um "reservatório de representações" das percepções, se organizando durante o desenvolvimento como um sistema de ligação entre as representações mentais, carregadas de seus afetos. A somatização estaria relacionada com a insuficiência desse sistema, o que gera limitação das representações e suas cargas afetivas, empobrecimento da simbolização e diminuição da capacidade de associação de idéias.

Zimermam (1999) faz menção ao pensamento operatório como característica presente nos pacientes somatizadores, que é caracterizado por um estado mental em que esses pacientes "superinvestem libidinalmente tudo aquilo que existe de concreto como, e principalmente, seus sintomas corporais" (p. 241). Incapaz de lidar psiquicamente com uma carga excessiva de sentimentos e pensamentos, o indivíduo responde com o agir ao invés do pensar devido à falta de condições do inconsciente expressar-se por meio das representações. Comparando o adulto psicossomático a um bebê, McDougall (1996) diz que ambos possuem o mesmo funcionamento psíquico diante de dolorosas emoções, reagindo apenas psicossomaticamente, articulando-se por meio de significantes não-verbais, sendo o sintoma a sua linguagem.

\section{O câncer e a psico-oncologia}

O câncer é uma doença que se desenvolve no próprio organismo, a partir de suas células, porém com uma estrutura diferente. Durante toda a vida, essas células anormais (neoplásicas ou não) surgem inúmeras vezes, sendo destruídas pelo sistema imunológico, que as identifica como alheias à normalidade. Em determinado momento, esse processo se modifica, fazendo com que o organismo reconheça como integrante de sua estrutura essa célula tumoral ou diferente. Portanto, ela não provocaria reações imunológicas e não seria eliminada. Esse mecanismo neoplásico acontece na intercomunicação entre os sistemas nervoso e imunológico, que se realiza pelos neurotransmissores gerados no cérebro, pelos hormônios produzidos pelo sistema endócrino e por células que regulam a resposta imune, como as citocinas (Gerardo, 2001).

Schávelzon (1992) menciona que condições psicológicas como o estresse ou a depressão podem ser causas dessa modificação no processo de identificação da célula diferente. Após esse processo, além de não eliminar a célula estranha, o organismo passa a atender as necessidades metabólicas do tumor. De acordo com Reiche, Nunes e Morimoto (2004), o estresse e a depressão geram a diminuição de citocinas, células T e células NK, afetando a vigilância imunológica contra tumores.

McDougall (1996) diz que nos estados psicossomáticos o corpo "hiperfunciona" ou inibe funções somáticas normais, como um "joguete da mente". Integrando as teorias de McDougall e de Schávelzon (1992), poderíamos hipotetizar que, no caso do câncer, o estresse e a depressão constituir-se-iam em desencadeantes de ações moleculares e enzimáticas que inibem a função do sistema imunológico de rejeitar a célula tumoral. Moreira (1998) fala da hiperreatividade e hipo-reatividade imunológica no aparecimento de doenças; essas alterações estariam envolvidas com mecanismos celulares e humorais da comunicação entre os sistemas endócrino e imunológico despertados pelo estresse. No câncer, sob a atuação do estresse, a célula T supressora pode ter sua atividade aumentada e privar o organismo de suas defesas eficazes.

Volich (2000) menciona constatações de diversos autores que indicam a diminuição do funcionamento do sistema imunológico em pessoas enlutadas e deprimidas, bem como sua correlação com a incidência ou o risco de câncer. Bartrop, Lazarus, Luckhurst, Kiloh e Penny (1977) também mostraram que um severo estresse, como o luto, pode reduzir a função imune.

Os mecanismos pelos quais fatores psicológicos afetam a função imune vêm sendo estudados pela Psiconeuroimunoendocrinologia, por meio da investigação das interações entre o comportamento e as emoções, o sistema nervoso central e os sistemas endócrino e imunológico (Glaser \& Kiecolt-Glaser, 2005; Maridsley \& Rampton, 2005; Schiepers, Wichers \& Maes, 2005; Tosevski \& Milovancevic, 2006). A comunicação entre esses sistemas é bidirecional (Fleshner \& Laudenslager, 2004; Glaser \& Kiecolt-Glaser, 2005; Schiepers e cols., 2005), realizada por meio de hormônios, neurotransmissores e citocinas (Vitetta, Anton, Cortizo \& Sali, 2005).

O Instituto Nacional de Câncer - INCa (2000) descreve a formação das neoplasias da seguinte forma:

As células dos diversos órgãos do nosso corpo estão constante-
mente se reproduzindo, isto é, uma célula adulta divide-se em
duas, (...) havendo o crescimento e a renovação das células
durante os anos (...) controladamente dentro das necessidades
do organismo. Porém, em determinadas ocasiões e por razões
ainda desconhecidas, certas células reproduzem-se com uma
velocidade maior, desencadeando o aparecimento de massas
celulares denominadas neoplasias ou, mais comumente, tumores
(grifos nossos).

São essas "determinadas ocasiões" e "razões desconhecidas" que mais têm interessado os pesquisadores. Alguns 
aspectos da personalidade podem estar relacionados com as mencionadas "razões desconhecidas"? Os eventos traumáticos que podem acontecer ao longo da vida estão relacionados com essas "determinadas ocasiões"? Essas são algumas perguntas que a psico-oncologia vem investigando.

A psico-oncologia atribui grande importância aos aspectos psicossociais na etiologia e desenvolvimento do câncer, defendendo um 'tratamento biopsicossocial' em que o enfoque seja dado ao indivíduo como um todo, e não apenas à doença (Épinay, 1988; Gimenez, 1994; Perestrello, 1996).

Segundo o INCa (2005), a gênese do câncer é variada e seus fatores podem ser externos ou internos estando inter-relacionados. Os fatores externos relacionam-se ao meio sociocultural, hábitos e costumes próprios. Os internos são, geralmente, geneticamente determinados e ligados à capacidade do organismo de se defender das agressões externas. Os fatores ambientais, denominados cancerígenos, alteram o DNA das células e estão relacionados com $80 \%$ dos casos de câncer.

$\mathrm{Na}$ psico-oncologia, essa gênese poderia ser ampliada considerando os fatores psicossociais além dos biológicos. Assim, os fatores externos poderiam ser não só substâncias químicas e afins, mas todos os eventos significativos para a vida psíquica do indivíduo. Com relação aos fatores internos, além das mutações genéticas, incluir-se-iam características de personalidade e estados afetivos, como estresse e depressão no processo de alteração das condições imunológicas, conforme evidenciado em pesquisas da Psiconeuroimunoendocrinologia (Caetano, D., Caetano \& Krämer, 1999; Glaser \& Kiecolt-Glaser, 2005; Oppermann, Alchieri \& Castro, 2002; Reiche, Nunes \& Morimoto, 2004; Tosevski \& Milovancevic, 2006).

Hulak e Lederman (1992) vêem o câncer e as demais manifestações psicossomáticas como patologias narcísicas, em que o paciente apresenta um falso self. Essas patologias apresentam posturas opostas no indivíduo: são altamente destrutivas, porém comportam um intenso desejo de viver, numa tentativa de, pela doença somática, matar o seu falso self. Seria um "suicídio psíquico da negação de si mesmo". Hulak e Lederman dizem que "Tánatos seria um mero instrumento de Eros e certas condições mórbidas seriam compreendidas como um apelo à vida e ao direito de viver." (p.338).

\section{Câncer de mama e do aparelho digestório}

No Brasil, o câncer de mama representa a primeira causa de morte por câncer entre as mulheres (INCa, 2000). Do ponto de vista psicológico, Pettingale (conforme citado por Volich, 2000) aponta para a repressão de emoções, principalmente as de caráter agressivo, como importantes em sua etiologia.

O câncer do aparelho digestório engloba uma ampla gama de cânceres: esôfago, estômago, intestino delgado, pâncreas, colorretal (intestino grosso, incluindo os segmentos cólon e reto), vesícula e vias biliares, fígado e anal (Onconews, 2001). Essa patologia, ao contrário do câncer de mama, não é muito citada em seus aspectos psicossomáticos, porém muita literatura é encontrada sobre a natureza psicossomática de desordens, como a gastrite ou a úlcera, que podem ser responsáveis pelo princípio de um câncer do estômago (Onconews, 2001).
Com relação aos pacientes com úlcera gástrica, Alexander (1989) constatou uma situação de conflito típica que pode manifestar-se em muitas personalidades diferentes. Ele observou um conflito entre o desejo de permanecer na situação dependente infantil de ser amado e protegido e o orgulho e a aspiração por independência, realização e auto-suficiência do ego adulto. A repressão da necessidade de dependência e do anseio por amor é "o estímulo psicológico inconsciente diretamente vinculado aos processos fisiológicos que, finalmente, levam à ulceração." (p.81).

A literatura revisada permite reconhecer alguns fatores psicológicos envolvidos na formação do câncer, tais como situações de perdas significativas, dificuldades em lidar com impulsos agressivos, estresse, tendência à negação e repressão dos afetos, entre outros coexistentes com as determinações genéticas e ambientais. Diante dessas constatações, a presente pesquisa tencionou investigar se tais fatores seriam comuns a diferentes tipos de câncer ou se cada neoplasia apresentaria suas peculiaridades do ponto de vista psicológico. No caso específico deste estudo, verificou-se as similaridades e diferenças psicológicas entre mulheres com câncer de mama e do aparelho digestório, num estudo comparativo.

\section{Método}

\section{Participantes}

Quinze mulheres diagnosticadas com câncer há no mínimo 6 meses, atendidas em um hospital público, com idade entre 41 e 60 anos, foram divididas em dois grupos: um composto por 10 mulheres com câncer de mama (CM) e outro por cinco mulheres com câncer do aparelho digestório (CAD). A diferença entre os grupos quanto ao número de sujeitos ocorreu devido à dificuldade em encontrar mulheres com CAD que atendessem aos requisitos de idade e tempo do diagnóstico. As participantes encontravam-se em fase ambulatorial, com retornos apenas para acompanhamento de rotina, com exceção de duas mulheres do grupo CM, que estavam no último mês da quimioterapia. Uma vez que Aarstad, H. J., Heimdal, Aarstad e Olofsson (2002) não constataram relação entre o estadiamento do câncer e as características de personalidade, esse critério não foi considerado para a seleção das participantes.

No grupo CM, as mulheres tinham idade entre 42 e 60 anos (média de 48,4 anos). A maioria era casada (6), católica (6) e com ocupação de dona de casa (6). A renda média do grupo era de 2,39 salários mínimos e todas vinham de famílias grandes, sendo que nove tinham mais de cinco irmãos. O grau de instrução variou do analfabetismo até o terceiro grau incompleto.

O grupo CAD apresentou idades entre 41 e 60 anos (média de 49,2 anos). O estado civil foi bem variado, sendo uma delas solteira, outra desquitada, amasiada, casada e viúva. Todas tinham mais de cinco irmãos e quatro delas eram evangélicas. A escolaridade variou da segunda série do ensino fundamental até o ensino médio incompleto, sendo que apenas duas mulheres eram donas de casa. A renda média era de 3,23 salários mínimos. Os tipos de CAD apresentados foram estômago (2), reto (2) e vesícula biliar (1). 


\section{Instrumentos}

- Entrevista psicológica com o suporte de um roteiro semiestruturado que visou à coleta dos dados da história pessoal e familiar da paciente e do seu processo de adoecer (anexo 1).

- Forma reduzida, organizada pelas pesquisadoras, do Teste de Apercepção Temática (T.A.T.), desenvolvido por Morgan e Murray (1935), composto pelas seguintes pranchas: $2,4,6 \mathrm{MF}, 3 \mathrm{MF}, 7 \mathrm{MF}, 8 \mathrm{MF}, 13 \mathrm{HF}, 14,18 \mathrm{MF}$ e 16 . Tais lâminas foram selecionadas para investigar conteúdos como relacionamento com a figura materna, modo de lidar com frustrações e agressividade, qualidade das relações objetais, entre outros apontados na literatura como relevantes para o surgimento do câncer. As pranchas foram apresentadas na ordem enumerada acima, visando a melhor fluência e continuidade dos temas abordados. A aplicação foi individual, realizada em sala reservada do hospital, sendo respeitadas as normas relativas à situação de aplicação de testes. O tempo médio de aplicação foi de 25 minutos.

\section{Procedimento}

Em função da ausência de parâmetros na literatura, as pesquisadoras estabeleceram como intervalo mínimo entre o diagnóstico das neoplasias e a aplicação das técnicas de avaliação psicológica o período de seis meses, para que o impacto causado pela notícia do diagnóstico não interferisse intensamente nos resultados, supondo que após esse período ele estivesse amenizado. Nas pacientes CM, o intervalo de seis meses foi contado após a mastectomia, para também diminuir o impacto da recente cirurgia.

Após a aprovação do projeto pelo Comitê de Ética da Faculdade de Filosofia, Ciências e Letras de Ribeirão Preto da Universidade de São Paulo e a assinatura do Termo de Consentimento Livre e Esclarecido, as pacientes foram entrevistadas numa sala reservada do hospital, antes ou depois de serem atendidas pelo médico. $\mathrm{O}$ mesmo procedimento foi seguido nas aplicações do T.A.T., que aconteciam no retorno seguinte da paciente ao hospital. As aplicações de ambas as técnicas foram audiogravadas e, posteriormente, transcritas integral e literalmente, acompanhadas de observações clínicas.

\section{Análise dos dados}

Todas as entrevistas foram submetidas a uma interpretação clínica de base psicanalítica, mediante supervisão da segunda autora. Os dados procedentes tanto da informação bruta (manifesta) referida pelas participantes quanto da interpretação realizada foram submetidos a uma análise de conteúdo mediante a seleção de categorias temáticas definidas a posteriori, conforme modelo proposto por Figueiredo (2000).

A avaliação dos protocolos do T.A.T. foi realizada em dois tempos: primeiramente, as estórias foram categorizadas de acordo com os critérios definidos por Morval, conforme apresentados por Jaquemin e Barbieri (2003). Posteriormente, foi feita uma análise clínica dos conteúdos de cada narração, também sob o referencial psicanalítico.

Em seguida, houve a integração dos dados da entrevista e do T.A.T., organizando-se uma síntese de cada paciente, indicativa dos principais conflitos e defesas utilizadas, da natureza das relações de objeto, instância dominante da personalidade e qualidade da angústia. Definia-se então a estrutura de personalidade de cada paciente, segundo referencial teórico de Bergeret (1998).

Os dados são apresentados tanto isoladamente para cada técnica, como de modo integrado, nas sínteses. Foi definido o número de pacientes que fizeram referência a cada uma das categorias definidas; como essas não eram mutuamente excludentes, uma mesma participante pode ser incluída em mais de uma delas.

\section{Resultados}

As principais informações fornecidas pela entrevista psicológica (relato verbal e interpretação) das mulheres de ambos os grupos podem ser visualizadas na Tabela 1 .

Observa-se que algumas características estão presentes de forma quase unânime nos dois grupos, como os relatos de perdas reais de entes queridos, frustrações na história pessoal anterior à doença, sucessão de eventos difíceis e rigidez na educação. No que concerne às características de personalidade, chama a atenção a dificuldade de elaboração psíquica e de integração das pulsões agressivas no self, bem como a

Tabela 1. Principais conteúdos relatados e características de personalidade das mulheres CM e CAD, conforme avaliados a partir das entrevistas.

\begin{tabular}{|c|c|c|c|}
\hline \multicolumn{2}{|c|}{ Informações do relato verbal } & $\mathbf{C M}$ & CAD \\
\hline \multirow{6}{*}{$\begin{array}{l}\text { Relatos de eventos } \\
\text { difíceis na história } \\
\text { pessoal anteriores } \\
\text { à doença }\end{array}$} & $\begin{array}{l}\text { Perda de entes queridos por morte } \\
\text { ou separação }\end{array}$ & 10 & 5 \\
\hline & $\begin{array}{l}\text { Frustrações, decepções e } \\
\text { desgostos }\end{array}$ & 10 & 5 \\
\hline & $\begin{array}{l}\text { Sucessão de outros eventos } \\
\text { difíceis }\end{array}$ & 9 & 5 \\
\hline & $\begin{array}{l}\text { Rigidez na educação e falta de } \\
\text { 'diálogo' }\end{array}$ & 8 & 4 \\
\hline & Traição do cônjuge & 6 & 3 \\
\hline & Perda por morte & 7 & 1 \\
\hline \multirow{5}{*}{$\begin{array}{l}\text { Fatores associados } \\
\text { pelas pacientes ao } \\
\text { início do câncer }\end{array}$} & $\begin{array}{l}\text { Raiva, mágoa e angústia } \\
\text { acumuladas }\end{array}$ & 5 & 4 \\
\hline & Perda por separação / traição & 2 & 1 \\
\hline & $\begin{array}{l}\text { Dificuldade no manejo da } \\
\text { agressividade (de integração das } \\
\text { pulsões agressivas no self) }\end{array}$ & 10 & 5 \\
\hline & Clivagem do ego - razão / afeto & 10 & 5 \\
\hline & $\begin{array}{l}\text { Dificuldade de elaboração } \\
\text { psíquica }\end{array}$ & 10 & 5 \\
\hline \multirow{6}{*}{$\begin{array}{l}\text { Características } \\
\text { de personalidade } \\
\text { avaliadas pelas } \\
\text { autoras }\end{array}$} & Conformismo e passividade & 10 & 4 \\
\hline & Religiosidade & 9 & 5 \\
\hline & Sentimento de desamparo & 9 & 2 \\
\hline & Pensamento operatório & 8 & 5 \\
\hline & $\begin{array}{l}\text { Ganho secundário: mais atenção, } \\
\text { cuidado e apoio da família }\end{array}$ & 8 & 5 \\
\hline & $\begin{array}{l}\text { Sentimento de impotência diante } \\
\text { das situações }\end{array}$ & 4 & 3 \\
\hline
\end{tabular}


clivagem do ego entre razão e afeto. Também a religiosidade, o conformismo, a passividade e o ganho secundário da doença se mostraram fortemente presentes em ambos os grupos.

No grupo CM, sete entre as 10 mulheres associaram o início do câncer a alguma perda por morte de um ente querido, trazendo à tona a dificuldade de elaborar o luto e todo o leque de sentimentos nele envolvidos. Já no grupo CAD, quatro das cinco mulheres relacionaram o surgimento da doença com sentimentos guardados (não digeridos) e acumulados, tais como mágoa, nervosismo, raiva, angústia e tristeza.

É possível que essa dificuldade de lidar com os sentimentos, relatada por ambos os grupos, esteja associada ao prejuízo na capacidade de representar psiquicamente as pulsões e de manejá-las, o que é passível de conduzir à sua descarga direta no soma, levando à produção do fenômeno psicossomático.

As características psicodinâmicas mais prevalentes em ambos os grupos, conforme indicadas na análise do T.A.T., são descritas na Tabela 2 .

Tabela 2. Principais características psicodinâmicas nos grupos de mulheres $\mathrm{CM}$ e CAD conforme avaliadas no T.A.T.

\begin{tabular}{lcc}
\hline \multicolumn{1}{c}{ TAT } & CM & CAD \\
\hline Estabelecimento de relações de dependência & 10 & 5 \\
Conflito entre dependência X independência & 9 & 4 \\
Dependência anaclítica do objeto & 7 & 1 \\
Pensamento operatório & 10 & 5 \\
Conflito com figura materna & 9 & 4 \\
Conflito nas relações heterossexuais & 9 & 5 \\
Conflitos relacionados ao Complexo de Édipo & 7 & 5 \\
Conflito com figura paterna & 6 & 1 \\
$\begin{array}{l}\text { Dificuldade em lidar com agressividade } \\
\text { Controle excessivo dos afetos }\end{array}$ & 5 & 3 \\
$\begin{array}{l}\text { Capacidade para buscar objetivos prejudicada } \\
\text { pela invasão dos afetos ou pela espera da ação } \\
\text { do outro }\end{array}$ & 6 & 3 \\
\hline
\end{tabular}

Notam-se algumas semelhanças entre os grupos como a existência de dependência do objeto e de conflitos com as figuras parentais e nos vínculos heterossexuais. A reação de muitas mulheres às pranchas relativas à temática edipiana $(2,4,6,7,13)$ sugere que pelo menos parte dessa problemática vincular encontra-se enraizada nos conflitos referentes à triangulação, mesmo nos casos em que a etapa edípica foi apenas entrevista, e não vivida de fato (organizações borderline). Essa tabela também deixa evidente a existência do pensamento operatório.

A tabela 3 exibe os resultados da avaliação integrada das entrevistas e do T.A.T., relativa aos critérios para a definição da estrutura de personalidade.

Verifica-se que, além da repressão como mecanismo de defesa mais utilizado pelas mulheres das duas amostras, no grupo CM houve predomínio de defesas psicóticas como a projeção (8) e a negação (7), enquanto no grupo CAD
Tabela 3. Análise integrada dos dados das entrevistas e do T.A.T. nos grupos de mulheres CM e CAD.

\begin{tabular}{|c|c|c|c|}
\hline \multicolumn{2}{|c|}{$\begin{array}{c}\text { Elementos concernentes à organização da } \\
\text { personalidade }\end{array}$} & \multirow{2}{*}{$\frac{\mathbf{C M}}{10}$} & \multirow{2}{*}{$\frac{\text { CAD }}{5}$} \\
\hline \multirow{11}{*}{$\begin{array}{l}\text { Mecanismos } \\
\text { de defesa mais } \\
\text { freqüentes }\end{array}$} & Repressão & & \\
\hline & Evitação & 8 & 1 \\
\hline & Projeção & 8 & 2 \\
\hline & Negação & 7 & 2 \\
\hline & Dissociação & 7 & 3 \\
\hline & Deslocamento & - & 3 \\
\hline & Idealização & - & 4 \\
\hline & Isolamento & - & 5 \\
\hline & Anulação & - & 3 \\
\hline & Formação Reativa & - & 2 \\
\hline & Racionalização & - & 4 \\
\hline \multirow{3}{*}{$\begin{array}{l}\text { Tipo de conflito } \\
\text { predominante }\end{array}$} & Ideal de ego X Id / Realidade & 7 & 1 \\
\hline & Id X Superego & 2 & 4 \\
\hline & Id X Realidade & 1 & - \\
\hline \multirow{3}{*}{$\begin{array}{l}\text { Nível de } \\
\text { desenvolvimen-to } \\
\text { egóico }\end{array}$} & $\begin{array}{l}\text { Ego anaclítico, imaturo e } \\
\text { fragilizado; ultrapassa vivências } \\
\text { psicóticas, mas não alcança o } \\
\text { Complexo de Édipo }\end{array}$ & 7 & 1 \\
\hline & $\begin{array}{l}\text { Ego mais desenvolvido, com } \\
\text { maior grau de integração }\end{array}$ & 2 & 4 \\
\hline & Ego não integrado & 1 & - \\
\hline \multirow{3}{*}{$\begin{array}{l}\text { Instância } \\
\text { dominante da } \\
\text { personalidade }\end{array}$} & Ideal de ego & 7 & 1 \\
\hline & Superego & 2 & 4 \\
\hline & Id & 1 & - \\
\hline \multirow{3}{*}{ Tipo de angústia } & Perda do objeto & 7 & 1 \\
\hline & Castração & 2 & 4 \\
\hline & Fragmentação & 1 & - \\
\hline \multirow{3}{*}{$\begin{array}{l}\text { Figuras materna e } \\
\text { paterna vistas como }\end{array}$} & $\begin{array}{l}\text { Cuidadores de apoio e não } \\
\text { objetos sexuais }\end{array}$ & 7 & 1 \\
\hline & $\begin{array}{l}\text { Objetos sexuais, relação } \\
\text { triangular edípica }\end{array}$ & 2 & 4 \\
\hline & Objetos não diferenciados do eu & 1 & - \\
\hline \multirow{3}{*}{ Relação de objeto } & Anaclítica & 7 & 1 \\
\hline & Genital & 2 & 4 \\
\hline & Fusional & 1 & - \\
\hline \multirow{3}{*}{$\begin{array}{l}\text { Estruturas de } \\
\text { personalidade }\end{array}$} & Borderline & 7 & 1 \\
\hline & Neurótica & 2 & 4 \\
\hline & Psicótica & 1 & - \\
\hline
\end{tabular}

prevaleceram defesas neuróticas como o isolamento (5) e a racionalização (4).

A comparação entre as Tabelas 1, 2 e 3 permite explicar a diferença marcante entre os grupos quanto ao sentimento de desamparo (Tabela 1), que está fortemente presente nas mulheres CM (9), em contraste com as CAD (2). Essa diferença está relacionada com os aspectos de dependência anaclítica (Tabela 2) e com a angústia de perda do objeto (Tabela 3) que predominam nas mulheres CM (7), mas não nas CAD (1). O anaclitismo implica uma relação primitiva com o objeto, em que este é visto como apoio e não como sexualizado e independente (Tabelas 2 e 3). Essa dependência anaclítica intensifica a angústia de perda do objeto, explicando a vivência de desamparo na maior parte do grupo CM. Vale dizer que as mulheres dos dois grupos (nove no CM e quatro no 
CAD) apresentaram conflito entre a necessidade de depender do outro e a de sair dessa dependência (Tabela 2).

Entre os demais conflitos avaliados nos grupos, destacamse os relacionados ao vínculo com a figura materna, ao relacionamento heterossexual e à integração das pulsões sexuais e agressivas no self (Tabelas 1 e 2). A importante presença do pensamento operatório (Tabela 1) parece decorrente, tanto da forte repressão dos afetos como da imaturidade do ego no caso do grupo CM (Tabela 3). Essas condições dificultam as vivências afetivas e o contato profundo consigo mesmo, prejudicando o desenvolvimento ou a atualização da capacidade de fantasiar e simbolizar.

Por meio das defesas mais utilizadas, da instância dominante da personalidade e dos conflitos a ela relacionados, do tipo de angústia predominante e da relação de objeto estabelecida, foi possível concluir que, das 10 mulheres do grupo $\mathrm{CM}$, sete apresentaram organização de personalidade borderline; por sua vez, no grupo $\mathrm{CAD}$, das cinco mulheres, quatro apresentaram estrutura neurótica (tabela 3 ).

\section{Discussão}

Embora os resultados mostrem diferenças entre os grupos, no que se refere à estrutura de personalidade predominante, $\mathrm{o}$ fato de existirem, dentro de cada uma das amostras, mulheres com organizações diversas vai ao encontro da hipótese de que a psicossomatização pode ocorrer em qualquer indivíduo diante de uma carga excessiva de afetos que não consegue manejar (Marty, 1993; McDougall, 1987, 1996; Zimermam, 1999). McDougall (1987) aponta para a "possibilidade de qualquer indivíduo manter o equilíbrio psíquico por meio de somatizações, quando as defesas neuróticas e psicóticas (...) falham ou tropeçam em seu funcionamento." (p.135).

Ainda, apesar da diferença estrutural, os grupos apresentaram muitas semelhanças em relação à sua história de vida, como perdas, frustrações e decepções, que não foram elaboradas ou integradas à personalidade. Presume-se que as vivências dessas adversidades da realidade ultrapassaram as condições psíquicas dessas mulheres, e que suas defesas não foram suficientes para enfrentá-las, recorrendo a mecanismos mais primitivos, como a regressão psicossomática (Bergeret, 1998).

Ambas as amostras mostraram dificuldades importantes em lidar com as pulsões agressivas, que não são elaboradas, expressas, nem se encontram integradas ao self. Essa agressividade seria fundamental na regressão psicossomática, já que não tendo outras vias de expressão ou representação psíquica, voltar-se-ia contra o próprio sujeito, sendo investida no soma.

Os resultados da amostra CM confirmam as pressuposições de Bergeret (1998) de que as psicossomatizações, embora possam existir em qualquer estrutura de personalidade, estão mais próximas das organizações borderline. Embora a distribuição do grupo CAD, com $80 \%$ de estruturas neuróticas, contraponha-se a essa teoria, os dinamismos presentes nessas mulheres mostram que essa contradição é mais aparente do que real.

No grupo CAD, as personalidades de estrutura neurótica poderiam ter apresentado regressões a outros tipos de defesas e até mesmo a um funcionamento mais próximo da organi- zação borderline em situações em que o estresse emocional ultrapassou suas condições psicológicas de enfrentamento. Assim, um ponto em comum nas mulheres de ambos os grupos seria a regressão, seja da estrutura neurótica ou da organização borderline a um funcionamento psicossomático muito primitivo.

Uma hipótese explicativa do vínculo entre organização borderline e transtorno psicossomático é a de que a necessidade de estabelecer e permanecer nas relações de objeto anaclíticas gera a angústia de perda do objeto, que levaria o indivíduo à depressão. Viriam, então, como mecanismos de defesa auxiliares, o pensamento operatório (investimento no concreto) e a alexitimia (não pensar o sentir), evitando entrar em contato com conteúdos que o ego não suportaria, pois é fragilizado e imaturo. Seria um esvaziamento do mundo psíquico para se proteger da depressão.

Esses indivíduos vivenciam uma luta interna constante, pois precisam sair da dependência angustiante do outro, que ao mesmo tempo é sentida como necessária. Essa luta também é impulsionada pelo narcisismo, que concebe a dependência como uma ferida narcísica, gerando ódio em relação ao objeto anaclítico. Eles demonstram sua agressividade indiretamente por grandes exigências que fazem ao outro, causando nestes sentimentos de culpa, caso não as satisfaça. Seria o único tipo de agressividade permitida já que, se expressa claramente, poderia causar a temida perda do objeto, além de contrariar as exigências do ideal de ego de 'ser uma pessoa boa'.

Segundo Bergeret (1998), as organizações borderline são caracterizadas pela presença de um "trauma desorganizador precoce" no início da fase edípica, que acarretaria uma pseudolatência do desenvolvimento libidinal, já que o complexo de Édipo é 'saltado', constituindo-se um ego fragilizado. Esse ego, diante de um "trauma desorganizador tardio" (na maturidade), teria um acesso agudo de angústia que, no caso das mulheres estudadas, teria sido enfrentado por meio da regressão psicossomática.

A separação entre afeto e razão na personalidade, presente em todas as mulheres, pode ser entendida como um mecanismo de clivagem entre a 'parte adaptada' (razão) e a 'parte não adaptada' (afetos) do ego, com o intuito de manter o equilíbrio psíquico. Os eventos trágicos na história de vida dessas pacientes, somados aos seus poucos recursos de elaboração afetiva, podem ameaçar esse equilíbrio por meio de uma ruptura dessa clivagem, já que as defesas empregadas satisfatoriamente até então (como o pensamento operatório) não são mais suficientes para mantê-lo. Com isso, a psicossomatização entraria como 'último' recurso para a proteção dessa clivagem e manutenção do "equilíbrio psíquico" (Dejours, 1988), visto que ela é a regressão mais profunda e primária que o indivíduo pode fazer (McDougall, 1987). Considerando que toda a amostra apresentou esse mecanismo de clivagem do ego (razão / afeto), essa dinâmica de manutenção do 'equilíbrio psíquico' aparece como independente da organização de personalidade instaurada. Dejours (1988) afirma que

(...) qualquer estrutura, na medida em que há clivagem, e na medida em que a zona de sensibilidade do inconsciente está protegida pela negação, é susceptível de reagir à prova da 
realidade por uma somatização, por uma atuação violenta ou por uma alucinação. (...) Os neuróticos, por melhor mentalizados que sejam, também têm uma zona de fragilidade e a somatização é possível. (p.128).

Esse pode ser um ponto chave para entender a manifestação, na amostra estudada, do câncer em diferentes organizações de personalidade.

A relação de dependência que todas as participantes demonstraram estabelecer com os objetos está relacionada com dificuldades no processo de introjeção, que pode ter sido prejudicado pela relação conflituosa com a figura materna. Com a dificuldade de introjeção do "objeto bom", é preciso manter o objeto externo próximo (dependência). Essa problemática compromete o processo de elaboração dos lutos, intensificando as vivências de várias perdas que essas mulheres sofreram ao longo da vida.

No caso das participantes com estrutura neurótica de ambos os grupos, embora não esteja presente o temor à depressão como angústia dominante, também existem relações objetais de dependência, que nesses casos podem estar mais relacionadas com as dificuldades de introjeção do que com a angústia de perda do objeto.

Por outro lado, as relações de dependência também podem oferecer algum benefício. Estabelecendo a dependência, essas mulheres podem desenvolver sua capacidade de introjeção, não precisando futuramente desse tipo de relação para manter seu equilíbrio psíquico. Nesse sentido, o trabalho psicoterápico, ao fomentar e satisfazer essa necessidade de dependência, seria de importância fundamental.

A dificuldade no manejo da agressividade presente nas estruturas neuróticas, diferentemente da organização borderline, está relacionada ao medo da punição pelo superego e ao sentimento de culpa. Os impulsos agressivos estão fortemente reprimidos, sendo a punição e a culpa responsáveis pelo seu retorno sobre si e tendo papéis fundamentais na formação do câncer (doença de "autoagressão").

A forte repressão dos impulsos parece ter suas raízes na religiosidade dessas mulheres, fortemente presente antes mesmo do início da doença, e no estilo de educação que tiveram. Elas podem estar vinculadas ao desenvolvimento da doença, mas com funções diferentes nas pacientes de estrutura neurótica (suporte para o superego) e borderline (ideal de ego). Não obstante, os dados encontrados sugerem que a religião pode ser "uma faca de dois gumes", já que também deu forças para essas mulheres enfrentarem a doença e manterem a fé em sua recuperação.

Finalmente, no caso da estrutura psicótica encontrada em uma das pacientes da amostra CM, a ocorrência da somatização pareceu mais relacionada à sua indiferenciação somato-psíquica, e não a uma regressão psicossomática.

Com exceção desse fato, pode-se dizer que as duas amostras, no que se refere principalmente às histórias de vida e às características de personalidade, confirmaram as hipóteses da literatura psicossomática relativas à dificuldade de elaboração afetiva, presença de negação e repressão dos afetos, dificuldade no manejo da agressividade, más relações familiares e conjugais, existência de perdas significativas antecedendo a doença e prejuízos na simbolização, predominando o pensamento operatório.

A maioria dos autores defende que a psicossomatização ocorre em função da dificuldade de simbolização, oriunda da "insuficiência do sistema pré-consciente" em realizar representações (Marty, 1993). Apesar de essa característica estar fortemente presente em todas as mulheres da amostra, uma análise profunda dos dados abordando seus aspectos conflitivos, relacionais e as angústias subjacentes, permite arriscar a existência de uma relação simbólica entre seus principais conflitos e o local atingido pelos cânceres. No caso das pacientes borderline essa simbolização seria mínima, mais próxima da equação simbólica, já que os sintomas são expressos de maneira direta.

Assim, no grupo CM, as participantes demonstraram intensos conflitos com a própria feminilidade em seus aspectos maternais e sexuais, provenientes de uma relação não satisfatória com a mãe, sendo, portanto, muito anteriores ao câncer e à mastectomia. O câncer viria, então, como um ataque à feminilidade; seria atacar o "seio mau", podendo-se pensar numa introjeção da figura materna com predomínio dos aspectos persecutórios.

No grupo CAD, é possível arriscar uma relação entre os locais atingidos pelo câncer e os fatores associados pelas mulheres ao seu início, que são sentimentos de raiva e mágoa acumulados durante os anos. Como os cânceres do grupo CAD referem-se a órgãos com funções de expulsão e digestão, é viável fazer uma analogia com a dificuldade de "digerir e expulsar" esses sentimentos do psiquismo, deteriorando os órgãos em que eles estariam "alojados" simbolicamente.

Uma proposta psicoterapêutica para essas pacientes seria fundamental para o fortalecimento do seu psiquismo, ajudando-as a conhecerem os próprios sentimentos e proporcionando elementos para enriquecer o seu mundo interno. Somente a partir daí seria viável o uso de interpretações que, se realizadas antes desse fortalecimento do ego, podem ser muito prejudiciais, invasivas, e até mesmo causar outros fenômenos de psicossomatização. O objetivo seria ajudar na construção de representações psíquicas e fortalecimento da capacidade de simbolização.

\section{Considerações Finais}

Os grupos de câncer estudados apresentaram diferenças expressivas somente com relação à estrutura de personalidade e de seus critérios de definição.

A pesquisa mostrou que, além das semelhanças na história de vida, essas mulheres têm uma forma peculiar de enfrentar os eventos da realidade, com semelhantes dinâmicas internas, principalmente no que diz respeito às dificuldades de elaboração psíquica, de integração da personalidade, de manejo dos impulsos agressivos e de áreas conflitivas referentes à figura materna e aos relacionamentos heterossexuais. O pensamento operatório e a presença de perdas significativas antecedendo a doença, expressivamente presentes, confirmam a literatura psicossomática. Em suma, os resultados sugeriram que todos esses fatores psicológicos podem ter influência significativa no 
desenvolvimento do câncer, independentemente do órgão atingido.

As análises sinalizaram para diferentes estruturas de personalidade, com o predomínio da organização borderline no grupo CM e neurótica no CAD. Portanto, a despeito da estrutura, qualquer indivíduo pode recorrer a uma regressão psicossomática.

É importante enfatizar que os grupos apresentaram muitas semelhanças nas histórias de vida, nas características de personalidade, na repressão dos afetos, além dos tipos de vivência relacional e de conflitos. É possível que esses elementos estejam mais intimamente relacionados com as influências psicológicas no desenvolvimento do câncer do que a natureza das estruturas de personalidade.

Os resultados apontam para a importância de uma atenção psicoterápica às pacientes, concomitantemente a um atendimento médico que lhes ofereça um espaço seguro, tanto para a "construção" de seu mundo mental quanto para a expressão e aceitação dos afetos negados e reprimidos.

É fundamental a característica estável e sólida da relação terapêutica que se mantém a despeito dos afetos negativos que nela podem aparecer, que deverão ser abarcados e compreendidos como parte de sua natureza, sem o risco de desorganizá-la. Esse vínculo deve permitir a regressão e a revivência de etapas primitivas do desenvolvimento das pacientes, fornecendo uma nova figura de identificação passível de fortalecer as capacidades de introjeção e, em consequiência, o ego em seu enfrentamento das adversidades da vida.

\section{Referências}

Aarstad, H. J., Heimdal, J., Aarstad, A. K. H. \& Olofsson, J. (2002). Personality traits in head and neck squamous cell carcinoma patients in relation to the disease state, disease extent and prognosis. Acta Oto-laryngologica, 122, 892-899.

Alexander, F. (1989). Medicina psicossomática - princípios $e$ aplicações. Porto Alegre: Artes Médicas.

Bartrop, R. W., Lazarus, L., Luckhurst, E., Kiloh, L.G. \& Penny, R. (1977). Depressed lymphocyte function after bereavement. The Lancet, 16, 834-836.

Bergeret, J. (1998). A Personalidade Normal e Patológica. Porto Alegre: Artmed.

Caetano, D., Caetano, S. C. \& Krämer, M. H. (1999). Psiconeuroimunoendocrinologia. Jornal Brasileiro de Psiquiatria, 48(7), 307-314.

Dejours, C. (1988). O corpo entre a biologia e a psicanálise. Porto Alegre: Artes Médicas.

Épinay, M. L. (1988). Groddeck: a doença como linguagem. Campinas: Papirus.

Ferraz, F. C. (1997). Das neuroses atuais à psicossomática. Em F. C. Ferraz \& R. M. Volich (Orgs), Psicossoma-psicossomática psicanalítica (pp. 23-38). São Paulo: Casa do Psicólogo.

Figueiredo, M. A. C. (2000). Estudo das representações sobre AIDS em pacientes para formação profissional visando grupos de suporte para pessoas contaminadas pelo HIV, sintomáticas ou não. Jornal Brasileiro de AIDS, 1(5), 22-32.

Fleshner, M. \& Laudenslager, M.L. (2004). Psychoneuroimmunology : then and now. Behavioral and Cognitive Neuroscience Reviews, 3(2), 114-130.
Freud, S. (1997). O ego e o id. Rio de Janeiro: Imago. (Trabalho original publicado em 1923)

Gerardo, H. (2001). Mente-cerebro: sus señales y su repercusión en el sistema inmunológico. Salud Mental, 24(1), 3-9.

Gimenez, M. G. G. (1994). Definição, foco de estudo e intervenção. Em M. M. M. L. Carvalho (Org.), Introdução à Psiconcologia (pp. 35-56). Campinas: Editorial Psy.

Glaser, R. \& Kiecolt-Glaser, J. K. (2005). Stress-induced immune dysfunction: implications for health. Nature Reviews Immunology, 5(3), 243-251.

Hulak, S. \& Lederman, G. (1992). Regênesis: o mito da Fênix em psicossomática. Em J. Mello Filho (Org.), Psicossomática hoje (pp. 335-339). Porto Alegre: Artes Médicas.

INCa (Instituto Nacional de Câncer)/Ministério da Saúde (2000). Retirado em 02/07/2000, http://www.inca.org.br.

INCa (Instituto Nacional de Câncer)/Ministério da Saúde (2005). Retirado em 20/11/2005, http://www.inca.org.br.

Jaquemin, A. \& Barbieri, V. (2003). O Teste de Aperceção Temática - TAT. Universidade de São Paulo, Ribeirão Preto.

Maridsley, J. E. \& Rampton, D. S. (2005). Psychological stress in IBD: new insights into pathogenic and therapeutic implications. Gut, 54(10), 1481-1491.

Marty, P. (1993). A psicossomática do adulto. Porto Alegre: Artes Médicas.

McDougall, J. (1987). Em defesa de uma certa anormalidade - teoria e clínica psicanalítica. Porto Alegre: Artes Médicas.

McDougall, J. (1996). Teatros do Corpo: o psicossoma em psicanálise. São Paulo: Martins Fontes.

Mello Filho, J. (1994). Concepção psicossomática: visão atual. Rio de Janeiro: Tempo Brasileiro.

Moreira, M. S. (1998). Mecanismos psicoimunológicos do crescimento tumoral. Jornal Brasileiro de Psiquiatria, 47(11), 567-573.

Morgan, C. \& Murray, H. A. (1935). A method for investigating fantasys: the Thematic Apperception Test. Archives of Neurology and Psychiatry, 34, 289-306.

Onconews (2001). Retirado em 05/12/2001, do http://www. onconews.com.br.

Oppermann, R. V., Alchieri, J. C. \& Castro, G. D. (2002). Efeitos do estresse sobre a imunidade e a doença periodontal. Revista da Faculdade de Odontologia de Porto Alegre, 43(2), 52-59.

Perestrello, D. (1996). A medicina da pessoa. São Paulo: Atheneu.

Reiche, E. M., Nunes, S. O. \& Morimoto, H. K. (2004). Stress, depression, the immune system, and cancer. The Lancet Oncology, 5(10), 617-625.

Schávelzon, J. (1992). Sobre psicossomática e câncer. Em J. Mello Filho (Org.), Psicossomática hoje (pp. 215-226). Porto Alegre: Artes Médicas.

Schiepers, O. J., Wichers, M. C. \& Maes, M. (2005). Cytokines and major depression. Progress in Neuropsychopharmacology and Biological Psychiatry, 29(2), 201-217.

Tosevski, D. L. \& Milovancevic, M. P. (2006). Stressful life events and physical health. Current Opinion in Psychiatry, 19(2), 184-189.

Vieira, W. C. (1997). A psicossomática de Pierre Marty. Em F. C. Ferraz \& R.M. Volich (Orgs), Psicossoma - psicossomática psicanalítica (pp. 15-22). São Paulo: Casa do Psicólogo. 
Vitetta, L., Anton B., Cortizo F. \& Sali A. (2005). Mind-body medicine: stress and its impact on overall health and longevity. Annals of the New York Academy of Sciences, 1057, 492-505.

Volich, R. M. (2000). Psicossomática: de Hipócrates à psicanálise. São Paulo: Casa do Psicólogo.

Zimermam, D. E. (1999). Fundamentos psicanalíticos: teoria, técnica e clínica - uma abordagem didática. Porto Alegre: Artmed.
Recebido em 15.08.2005

Primeira decisão editorial em 24.11.2005

Versão final em 02.05.2007

Aceito em 15.06.2007 
Anexo 1. Roteiro da Entrevista Psicológica.

I. Dados de Identificação:

Nome:

Data de nascimento:

Estado civil:

Procedência:

Profissão:

Renda líquida:

Pai:

Escolaridade:

Mãe:

Escolaridade:

Cônjuge:

Escolaridade:

II. História da Doença Atual

III. Doenças Anteriores

IV. História Familiar

V. História Pessoal Pregressa

$\Rightarrow$ Informações disponíveis sobre os períodos Pré-natal e Perinatal

$\Rightarrow$ Infância

$\Rightarrow$ Período Escolar

$\Rightarrow$ Adolescência

$\Rightarrow$ Idade Adulta

$\Rightarrow$ Vida Atual
Idade:

Sexo:

Naturalidade:

Instrução:

Trabalho:

Religião:

Idade:

Profissão:

Idade:

Profissão:

Idade:

Profissão: 